\title{
Prototipe Sistem Monitoring Konsumsi Energi Listrik serta Estimasi Biaya pada Peralatan Rumah Tangga Berbasis Internet of Things
}

\author{
Mohamad Nursamsi Adiwiranto ${ }^{1}$, Catur Budi Waluyo ${ }^{1}$ \\ ${ }^{1}$ Program Studi Teknik Elektro Institut Teknologi Dirgantara Adisutjipto \\ *adiwirantosamsi@gmail.com
}

\begin{abstract}
Electricity has become a basic necessity for everyone. Including household appliances that use electrical energy. Monitoring equipment is needed to know how much power, energy, used and the estimated cost to be paid. The tool designed for this monitoring system uses a PZEM-004T sensor, the platform Ubidots and NodeMCU. The PZEM-004T sensor functions to measure the voltage, current, power, power factor, and energy contained in electrical loads. And NodeMCU is needed as a microcontroller. The results can be displayed on the platform Ubidots and the 16x2 LCD used. The test results obtained through measurements using the PZEM-004T sensor for designing a prototype energy monitoring system have a voltage accuracy value of 98.94\%, 99.18\% current, 98.87\% power, 98.44\% power factor, and 97 electrical energy consumption. , 89\%. In household electrical appliances (led lights, televisions, fans, ricecookers, and laptop chargers) the results of electrical energy consumption in a month are $43.56 \mathrm{kWh}$ and the estimated cost is $\mathrm{Rp} 114.781 .52$ with a total bill estimated by PLN of 113,567.7.
\end{abstract}

Keywords : Monitoring System, Ubidots, Electrical Monitoring Energy, PZEM-004T Sensor, Internet of Things.

\section{INTISARI}

Listrik sudah menjadi kebutuhan dasar setiap orang. Termasuk peralatan rumah tangga yang menggunakan energi listrik. Dibutuhkan alat monitoring agar diketahui berapa besar konsumsi energi yang digunakan dan estimasi biaya yang harus dibayarkan. Alat yang dirancang untuk sistem monitoring ini menggunakan sensor PZEM-004T, platform Ubidots serta NodeMCU. Sensor PZEM-004T berfungsi untuk mengukur tegangan, arus, daya, faktor daya dan energi yang terdapat pada beban listrik. Serta dibutuhkan NodeMCU sebagai mikrokontroler. Hasilnya dapat ditampilkan pada platform Ubidots dan LCD 16x2 yang digunakan. Dari hasil pengujian yang didapat melalui pengukuran menggunakan sensor PZEM-004T untuk perancangan prototipe sistem monitoring energi memiliki nilai akurasi tegangan sebesar 98.94\%, Arus 99.18\%, daya 98.87\%, faktor daya 98.44\%, serta konsumsi energi listrik 97.89\%. Selain daripada itu peralatan listrik rumah tangga (lampu led, televisi, kipas, ricecooker, dan charger laptop) didapatkan hasil konsumsi energi listrik dalam waktu sebulan sebesar 43.56 $\mathrm{kWh}$ dan estimasi biaya sebesar Rp 114.781.52 dengan jumlah tagihan sebenarnya yang ditagihkan oleh PLN sebesar 113.567 .7

Kata kunci: Sistem Pemantauan, Ubidots, Monitoring Energi Listrik, Sensor PZEM-004T, Intenet of Things.

\section{PENDAHULUAN}

Dimasa pandemi covid-19 seperti sekarang ini masyarakat mengeluhkan tagihan listrik yang membengkak saat Work from Home. Asumsi ini muncul karena masyarakat mengklaim konsumsi listrik yang mereka lakukan saat Work From Home samadengan hari-hari biasa. Hal ini disampaikan terkait lonjakan tagihan listrik yang sangat signifikan dibandingkan tagihan-tagihan sebelumnya. Energi listrik dibutuhkan untuk menunjang segala kehidupan manusia pada saat sekarang ini. Mulai dari pekerjaan di rumah tangga, perjalanan dan didalam pekerjaan. Tetapi, jika dalam penggunaan terdapat pemborosan atau penggunaan yang diluar kebiasaan menyebabkan pembayaran rekening listrik melambung tinggi.

Untuk mengatasi hal tersebut, harus dilakukan pengukuran energi listrik dalam penggunaannya, agar 
penggunaan enegi menjadi efisien dan berdaya guna baik. Namun untuk melakukan manajemen konsumsi energi listrik di rumah tidak cukup hanya dengan menggunakan $\mathrm{kWh}$ meter pascabayar saja, karena $\mathrm{kWh}$ meter pascabayar bertugas memonitor dan membatasi penggunaan listrik secara keseluruhan dirumah pelanggan, Penggunaan daya listrik bergantung pada pemakaian. Semakin banyak peralatan yang digunakan maka daya yang terpakai juga semakin besar sehingga dapat menyebabkan beban arus yang berlebih. Agar bisa melakukan manajemen listrik yang lebih baik dalam rumah tangga, maka diperlukan suatu perangkat elektronika yang dapat memonitor pemakaian energi listrik pada perangkat listrik yang dianggap cukup boros seperti setrika pakaian, lemari pendingin, penanak nasi, dispenser, mesin cuci dan televisi.

Setiap rumah yang terpasang listrik pasti terdapat $\mathrm{kWh}$ meter milik PLN, baik itu $\mathrm{kWh}$ meter pascabayar maupun $\mathrm{kWh}$ meter prabayar. Pencatatan pemakaian listrik menggunakan $\mathrm{kWh}$ meter pascabayar ini adalah dalam satuan Watt jam, yang sebagian masyarakat memang tidak paham mengkonversikannya ke biaya dalam rupiah, sehingga masyarakat tidak dapat memantau secara langsung listrik yang mereka pakai. Saat ini memantau energi listrik banyak dilakukan dengan memasang alat-alat ukur listrik pada rangkaian listrik sebelum masuk ke beban. Cara ini memiliki kekurangan, dimana untuk mengetahuinya harus langsung melihat ke lokasi tempat alat ukur dipasang sehingga tidak efisien karena tidak langsung diketahui hasilnya. Untuk itu perlu ditambahkan sebuah alat yang dapat digunakan untuk memantau dari jarak jauh[1],[8].

Penelitian ini merupakan pengembangan dari penelitian sebelumnya oleh [1]. Pada penelitian tersebut alat monitoring dikoneksikan pada Smartphone Android yang digunakan sebagai media interface user yang menampilkan komsumsi energi listrik. Berdasarkan hasil pengujian dapat disimpulkan bahwa hasil perancangan alat monitoring energi listrik memiliki angka simpangan (error) sebesar 1.07\%, arus $3.45 \%$, daya nyata $3.93 \%$, dan energi yang dikonsumsi $18.6 \%$.

Pada penelitian sebelumnya terdapat kekurangan pada nilai simpangan error pada daya nyata dan konsumsi energi yang masih tinggi dan belum terdapat estimasi biaya, sehingga perlu dilakukan adanya pengembangan. Pada penelitian ini dilakukan monitoring konsumsi energi untuk mempermudah konsumen energi listrik mengontrol penggunaan daya dan energi pada peralatan listrik rumah tangga sehingga mampu memanajemen penggunaan listrik dengan baik, serta dapat memperkirakan estimasi biaya pemakaian. Penelitian ini menggunakan NodeMCU ESP8266 sebagai mikrokontroler berfungsi untuk menerima data dari sensor PZEM004T dan mengirimkan data ke dalam database Ubidots sebagai platform IoT dan menampilkannya pada web browser.

\section{LANDASAN TEORI}

\section{A. Sistem Pembayaran Listrik PLN}

Sistem pembayaran listrik Pascabayar yaitu pelanggan menggunakan energi listrik dulu dan membayar belakangan, pada bulan berikutnya. Setiap bulan PLN harus mencatat meter, menghitung dan menerbitkan rekening yang harus dibayar pelanggan, melakukan penagihan kepada pelanggan yang terlambat atau tidak membayar, dan memutus aliran listrik jika pelanggan terlambat atau tidak membayar rekening listrik setelah waktu tertentu.

\section{B. Pengertian Daya Listrik}

Daya Listrik atau dalam bahasa Inggris disebut dengan Electrical Power adalah ukuran energi per satuan waktu. Oleh karena itu, daya memberikan tingkat konsumsi atau produksi energi. Satuan daya umumnya adalah watt (W), misalnya peringkat watt suatu alat menunjukkan laju penggunaan energi. Jumlah total energi yang dikonsumsi oleh alat ini adalah watt dikalikan dengan lamanya waktu digunakan; energi ini dapat dinyatakan dalam satuan watt hour (atau, lebih umum, kilowatt hour)[2][7].

\section{Daya Aktif}

Daya aktif atau daya nyata adalah daya sebenarnya yang dibutuhkan oleh beban. Daya aktif menunjukkan adanya aliran energi listrik dari pembangkit listrik ke jaringan beban untuk dapat dikonversikan menjadi energi lain. Satuan daya aktif adalah Watt[2]. Daya aktif dapat dihitung dengan Persamaan (1).

$$
\mathrm{P}=\mathrm{V} \cdot \mathrm{I} \cos \phi
$$

\section{Daya Reaktif}

Daya reaktif adalah daya yang dibutuhkan untuk membangkitkan medan magnet di kumparan 
kumparan beban induktif. Seperti pada motor listrik induksi misalnya, medan magnet yang dibangkitkan oleh daya reaktif. Satuan dari daya reaktif adalah Volt Ampere Reactive (VAR)[2]. Daya aktif dapat dihitung dengan Persamaan (2).

$\mathrm{Q}=\mathrm{V} . \mathrm{I} \sin \phi$

\section{E. Daya Semu}

Daya semu atau daya total (S), ataupun juga dikenal dalam Bahasa Inggris Apparent Power, adalah hasil perkalian antara tegangan efektif (root-meansquare) dengan arus efektif (root-mean-square). Satuan dari daya semu adalah Volt Ampere (VA)[2]. Daya semu dapat dihitung dengan menggunakan Persamaan (3).

$\mathrm{S}=\mathrm{V} . \mathrm{I}$

\section{F. Faktor Daya}

Faktor daya atau power factor adalah perbandingan antara daya aktif (watt) dengan daya semu (VA), atau cosinus sudut antara daya aktif dan daya semu. Daya reaktif yang tinggi akan meningkatkan sudut ini dan sebagai hasilnya faktor daya akan menjadi lebih rendah. Faktor daya selalu lebih kecil atau sama dengan satu. Semakin rendah faktor daya maka semakin sedikit daya yang kita manfaatkan dari daya semu yang tersedia[2]. Faktor daya dapat dihitung dengan menggunakan Persamaan (4).

Faktor daya $=\frac{\mathrm{P}(\mathrm{W})}{\mathrm{g}(\mathrm{VA})}$

\section{G. Internet of Things}

Internet of Things (IoT) adalah sebuah gagasan dimana semua benda di dunia nyata dapat berkomunikasi satu dengan yang lain sebagai bagian dari satu kesatuan sistem terpadu menggunakan jaringan internet sebagai penghubung. Dengan kata lain Internet of Things merupakan sebuah konsep dimana suatu objek yang memiliki kemampuan untuk pengiriman data atau informasi melalui jaringan tanpa memerlukan campur tangan manusia. IoT sangat erat hubungannya dengan komunikasi mesin dengan mesin (M2M) tanpa campur tangan manusia ataupun komputer yang lebih dikenal dengan istilah cerdas (smart)[3][6].

\section{H. NodeMCU}

NodeMCU pada dasarnya adalah pengembangan dari ESP8266 dengan firmware berbasis e-Lua. Pada NodeMCU dilengkapi dengan micro usb port yang berfungsi untuk memprogram maupun power supply. Selain itu juga pada NodeMCU dilengkapi dengan tombol push button yaitu tombol reset dan flash. NodeMCU menggunakan bahasa program Lua yang merupakan paket dari ESP 8266. Bahasa Lua memiliki logika dan susunan program yang sama dengan $\mathrm{c}$ hanya berbeda syntax. Jika menggunakan bahasa Lua maka dapat menggunakan tool Lua loader maupun Lua uploder[4].

\section{Sensor PZEM-004T}

Sensor PZEM-004T adalah sebuah modul sensor multifungsi yang berfungsi untuk mengukur tegangan, arus, daya, faktor daya dan energi yang terdapat pada sebuah aliran listrik. Modul ini sudah dilengkapi sensor tegangan dan sensor arus (CT) yang sudah terintegrasi. Dalam penggunaannya, alat ini khusus untuk penggunaan dalam ruangan (indoor) dan beban yang terpasang tidak diperbolehkan melebihi daya yang sudah ditetapkan[5][10].

\section{METODE PENELITIAN}

\section{A. Gambaran Umum}

Secara garis besar sistem monitoring biaya listrik terpakai menggunakan NodeMCU ESP8266 dan sensor PZEM-004T yang terintegrasi internet of things dengan aplikasi sistem monitoring, data hasil pembacaan disimpan ke aplikasi cloud Ubidots yang merupakan open IoT platform.

\section{B. Diagram Blok Sistem}

Dalam perancangan prototipe sistem monitoring energi, dibuat dalam bentuk diagram blok sistem yang dapat dilihat pada Gambar 1.

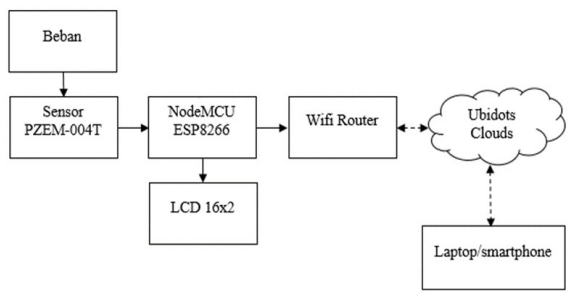

Gambar 1. Blok Diagram Sistem

Blok diagram pada Gambar 1 dapat dilihat bahwa beban yang digunakan adalah peralatan rumah tangga seperti: ricecooker, televisi, kipas angin dll. Beban 
Jurnal ELECTRON, Vol. 2, No.2, November 2021, Hal. 69-78

e-ISSN 2622-6588 / p-ISSN 2830-523X

DOI: 10.33019\electron.v2i2.2

yang diukur menggunakan sensor PZEM-004T. Data arus dan tegangan yang terbaca pada modul PZEM004T dibaca NodeMCU melalui port komunikasi tersebut, Protokol komunikasi yang digunakan mengikuti format protokol yang dimiliki oleh PZEM sehingga diperlukan pustaka pemprograman yang diperlukan untuk berkomunikasi dengan modul PZEM.

Aplikasi sistem monitoring energi memerlukan aplikasi server untuk menampung data hasil pembacaan. Pada tahap awal pengembangan data hasil pembacaan disimpan ke aplikasi cloud Ubidots yang merupakan open IoT platform. Dengan aplikasi ini maka dapat dipastikan aplikasi firmware pada NodeMCU sudah bekerja dengan benar.

Selanjutnya adalah platform Ubidots yang menampilkan data parameter listrik serta konsumsi energi. Untuk memberikan efek psikologis pada pengguna maka pada platform Ubidots dan layar LCD ditampilkan data besarnya biaya yang harus dikeluarkan berdasarkan konsumsi energi yang telah digunakan dan prediksi besarnya biaya yang dikeluarkan selama pemakaian jika berdasarkan besarnya konsumsi energi hingga saat itu. Jika total konsumsi energi hingga waktu $\mathrm{t}(\mathrm{jam})$ dinyatakan sebagai Etotal (t) dan biaya per $\mathrm{kWh}$ sebagai biaya tagihan.

\section{Perancangan Perangkat Lunak}

Perancangan perangkat lunak dilakukan dengan menggunakan NodeMCU ESP8266 sebagai mikrokontroler berfungsi untuk menerima data dari sensor dan mengirimkan data ke dalam database Ubidots sebagai platform IoT dan menampilkannya pada web browser. Sensor yang digunakan adalah PZEM-004T untuk mengetahui beberapa parameter listrik. Data yang telah didapatkan nantinya dapat diakses melalui web dan dapat dilihat juga pada LCD. Penggunaan database bertujuan untuk menyimpan data-data yang telah didapatkan pada sensor PZEM004T yang nantinya ditampilkan pada LCD dan web. Flowchart sistem monitoring dapat dilihat pada Gambar 2.

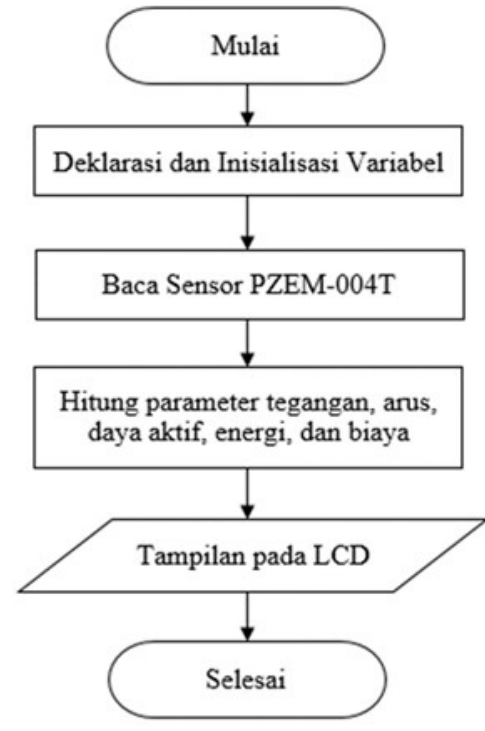

Gambar 2 Flowchart sistem monitoring

Data yang telah didapatkan dari sensor PZEM004T nantinya akan ditampilkan di web dalam bentuk angka tabel dan grafik. Berdasarkan dari perancangan dan sistem kerja alat, Jika sitem tidak terhubung koneksi internet, maka dilakukan penghubungan ulang. Jika sudah terhubung, maka dapat menerima data dan mengirimkannya ke database server. Jika data telah terkirim ke database server, maka dilakukan penyimpanan data ke tabel yang tersedia pada aplikasi antarmuka.

\section{Perancangan Perangkat Keras}

Perancangan perangkat keras merupakan perancangan pengkabelan rangkaian dari alat yang dibuat. Perancangan perangkat keras dimulai dengan pembuatan diagram blok sistem yang telah dirancang. Komponen utamanya menggunakan NodeMCU ESP8266. Sensor yang digunakan yaitu sensor PZEM004T yang berfungsi untuk mengukur parameter listrik. Menggunakan LCD1602 yang berfungsi menampilkan nilai yang telah diukur pada parameter listrik.

Parameter listrik yang akan diukur diantaranya: VRMS (V), IRMS (A), Daya Aktif (W), Faktor Daya $(\cos \phi)$, penggunaan energi listrik (dalam satuan $\mathrm{kWh}$ ), dan estimasi biaya penggunaan listrik (dalam satuan rupiah) dengan menggunakan sensor PZEM004T. Data yang telah didapatkan akan ditampilkan di LCD dan situs. Data tersebut selain ditampilkan di LCD dan situs langsung tersimpan di database 
Jurnal ELECTRON, Vol. 2, No.2, November 2021, Hal. 69-78

e-ISSN 2622-6588 / p-ISSN 2830-523X

DOI: $10.33019 \backslash$ electron.v2i2.2

Ubidots. Data yang telah tersimpan di basis data Ubidots dapat diakses melalui web browser. Gambar rangkaian pengkabelan dapat dilihat pada Gambar 3.

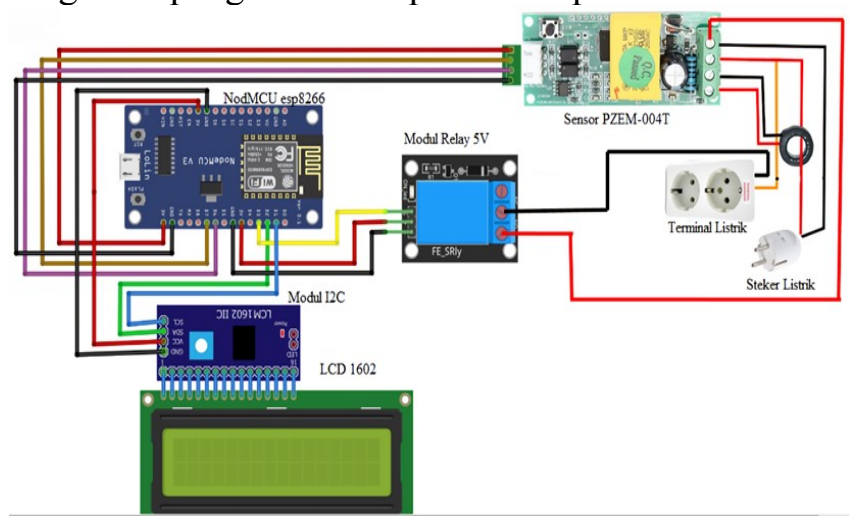

Gambar 3 Diagram pengkabelan Sistem

\section{E. Perancangan Internet of Things}

Perancangan Internet of Things (IoT) digunakan sebagai media interface alat dengan operator. Platform IoT yang digunakan adalah Ubidots [9]. Berikut adalah langkah-langkah untuk koneksi sistem dengan Ubidots: Buka situs Ubidots pada alamat www.ubidots.com klik sign in pada kolom atas dan masukkan username serta password. Tekan tombol sign in berwarna putih atau tekan enter pada keyboard setelah memasukkan password.

Setelah melakukan proses $\log$ in pilih tab device kemudian klik add device untuk menambah perangkat baru kedalam ubidots. Ganti nama perangkat sesuai yang diinginkan. Klik device yang baru saja dibuat untuk membuat variabel baru. Setelah device diklik maka muncul tampilan. Klik add variable kemudian pilih default pada toolbar yang muncul. Ganti nama variable sesuai yang diinginkan.

Untuk menambahkan variable lain cukup ulangi langkah ini kembali pada ikon Add Variable yang muncul. Klik username pada pojok kanan atas. Pilih API Credentials pada toolbar yang muncul untuk menampilkan token. Copy token ke program arduino IDE. Selanjutnya pada tampilan variable, klik ikon info untuk menampilkan variable ID. Copy variable ID ke program arduino IDE.

\section{HASIL PENELITIAN DAN PEMBAHASAN}

Pengujian alat dilakukan untuk dapat mengetahui hasil perancangan dan pembuatan alat. Pada bab ini akan dibahas tentang pengujian hasil dan analisa data dari pengujian sistem monitoring terhadap beban pada peralatan rumah tangga. Adapun data yang dianalisis pada pengujian alat adalah:

\section{A. Hasil Pengujian Beban Pada Alat Ukur Standar dan Rancangan}

Pengujian dilakukan dengan menggunakan beberapa beban peralatan rumah tangga. Beban yang digunakan diantaranya: ricecooker $350 \mathrm{~W}$, lampu led $12 \mathrm{~W}$, kipas angin $35 \mathrm{~W}$, televisi tabung $55 \mathrm{~W}$, dan juga charger laptop $45 \mathrm{~W}$. Pengujian yang dilakukan dari masing-masing beban yang digunakan untuk mengetahui nilai dari akurasi alat ukur rancangan.

\section{Hasil Pengujian Nilai Akurasi Pada Tegangan}

Setelah dilakukan pengambilan data dari masingmasing beban pada peralatan rumah tangga dengan alat ukur rancangan, diperoleh data pengujian tegangan yang menggunakan alat ukur rancangan dan alat ukur standar. Maka diperoleh hasil nilai akurasi dari alat ukur rancangan yang dibandingkan dengan alat ukur standar. Hasil dari masing-masing beban pada perangkat elektronik dapat dilihat pada Tabel 1.

Tabel 1 Hasil Pengujian Nilai Akurasi Pada Tegangan

\begin{tabular}{|c|c|c|c|c|}
\hline \multirow{2}{*}{ No } & \multirow{2}{*}{ Beban } & $\begin{array}{c}\text { Tegangan RMS (V) } \\
\text { Nilai rata- } \\
\text { rata alat } \\
\text { ukur } \\
\text { rancangan }\end{array}$ & $\begin{array}{c}\text { Nilai rata- } \\
\text { rata alat } \\
\text { ukur } \\
\text { standar }\end{array}$ & $\begin{array}{c}\text { Akurasi } \\
(\%)\end{array}$ \\
\hline 1 & $\begin{array}{c}\text { Lampu } \\
\text { Led 12W }\end{array}$ & 230.117 & 231.950 & 99.21 \\
\hline 2 & $\begin{array}{c}\text { Kipas } \\
\text { Angin } \\
35 W\end{array}$ & 230.700 & 229.083 & 99.29 \\
\hline 3 & $\begin{array}{c}\text { Televisi } \\
55 \mathrm{~W}\end{array}$ & 228.850 & 230.850 & 99.13 \\
\hline 4 & $\begin{array}{c}\text { Ricecooker } \\
350 \mathrm{~W}\end{array}$ & 226.583 & 226.683 & 99.96 \\
\hline 5 & $\begin{array}{c}\text { Charger } \\
\text { Laptop } \\
45 \mathrm{~W}\end{array}$ & 222.483 & 229.050 & \\
\hline \multicolumn{4}{|c|}{ Akurasi Rata-rata } & 97.13 \\
\hline
\end{tabular}

Dari tabel diatas merupakan hasil dari pengujian menggunakan alat ukur rancangan dengan menggunakan beberapa beban, yang dibandingkan 
dengan alat ukur standar. dapat dilihat nilai tegangan rata-rata dari masing-masing beban yang terukur pada alat ukur rancangan dan juga alat ukur standar.

$$
\begin{aligned}
\% \text { akurasi rata-rata } & =\frac{\sum \% \text { akurasi }}{m} \\
\% \text { akurasi rata-rata } & =\frac{494 . \% 2}{5} \\
\% \text { akurasi rata-rata } & =98.94 \%
\end{aligned}
$$

Sebagai contoh perhitungan menggunakan beban charger laptop dengan persentase akurasi tegangan sebesar $97.13 \%$. persentase nilai kesalahan yang diakibatkan kesalahan pembacaan dari alat ukur rancangan terhadap alat ukur standar. Dan dapat juga disebabkan naik turunnya tegangan pada saat pengukuran tegangan sehingga terdapat selisih pengukuran yang masih dalam tahap yang wajar. Persentase nilai akurasi rata-rata dalam pengukuran alat ukur rancangan terhadap alat ukur standar sebesar 98.94\%. Persentase kesalahan dalam pengujian pengukuran pembacaan tegangan yang terbaca pada alat ukur adalah sebesar $1.06 \%$. Nilai kesalahan tersebut masih dalam batas yang wajar karena kurang dari $5 \%[5]$.

\section{Hasil Pengujian Nilai Akurasi Pada Arus}

Setelah dilakukan pengambilan data dari masingmasing beban pada peralatan rumah tangga dengan alat ukur rancangan, diperoleh data pengujian arus yang menggunakan alat ukur rancangan dan alat -ukur

\begin{tabular}{|c|c|c|c|c|}
\hline \multirow[b]{2}{*}{ No } & \multirow[b]{2}{*}{ Beban } & \multicolumn{2}{|c|}{ Arus RMS (A) } & \multirow[b]{2}{*}{$\begin{array}{c}\text { Akurasi } \\
(\%)\end{array}$} \\
\hline & & $\begin{array}{l}\text { Nilai rata- } \\
\text { rata alat } \\
\text { ukur } \\
\text { rancangan }\end{array}$ & $\begin{array}{l}\text { Nilai rata- } \\
\text { rata alat } \\
\text { ukur } \\
\text { standar }\end{array}$ & \\
\hline 1 & $\begin{array}{c}\text { Lampu } \\
\text { Led } 12 \mathrm{~W}\end{array}$ & 0.072 & 0.073 & 98.63 \\
\hline 2 & $\begin{array}{c}\text { Kipas } \\
\text { Angin } \\
35 \mathrm{~W}\end{array}$ & 0.280 & 0.277 & 98.92 \\
\hline 3 & $\begin{array}{c}\text { Televisi } \\
55 \mathrm{~W}\end{array}$ & 0.282 & 0.285 & 98.95 \\
\hline 4 & $\begin{array}{c}\text { Ricecooker } \\
350 \mathrm{~W}\end{array}$ & 0.523 & 0.528 & 99.05 \\
\hline 5 & $\begin{array}{c}\text { Charger } \\
\text { Laptop } \\
45 \mathrm{~W}\end{array}$ & 0.218 & 0.217 & 99.54 \\
\hline \multicolumn{4}{|c|}{ Akurasi Rata-rata } & 99.18 \\
\hline
\end{tabular}
standar. Hasil dari masing-masing beban pada perangkat elektronik dapat dilihat pada Tabel 2.
Tabel 4.2 Hasil Pengujian Nilai Akurasi Pada Arus

Dari Tabel 2 merupakan hasil dari pengujian menggunakan alat ukur rancangan dengan menggunakan beberapa beban, yang dibandingkan dengan alat ukur standar. dapat dilihat nilai arus rata-rata dari masing-masing beban yang terukur pada alat ukur rancangan dan juga alat ukur standar. Untuk menghitung persentase nilai akurasi didapatkan sebagai berikut.

$$
\begin{aligned}
& \% \text { akurasi rata-rata }=\frac{\sum \% \text { akkurasi }}{\frac{\mathrm{m}}{05}} \\
& \% \text { akurasi rata-rata }=\frac{495}{5} \\
& \% \text { akurasi rata-rata }=99.18 \%
\end{aligned}
$$

Sebagai contoh perhitungan menggunakan beban Lampu led. Persentase akurasi arus sebesar 98.63\%. Persentase nilai kesalahan yang besar diakibatkan kesalahan pembacaan dari alat ukur rancangan terhadap alat ukur standar. Dan dapat juga disebabkan karena nilai arus pada beban yang sangat kecil, pada saat pengukuran arus sehingga terdapat selisih pengukuran yang masih dalam tahap yang wajar. Persentase nilai akurasi rata-rata dalam pengukuran alat ukur rancangan terhadap alat ukur standar sebesar $99.18 \%$. Persentase kesalahan dalam pengujian pengukuran pembacaan arus yang terbaca pada alat ukur adalah sebesar $0.82 \%$. Menurut [5] nilai kesalahan tersebut masih dalam batas yang wajar karena kurang dari 5\%.

2. Hasil Pengujian Nilai Akurasi Pada Faktor Daya Setelah dilakukan pengambilan data dari masing-masing beban pada peralatan rumah tangga dengan alat ukur rancangan, diperoleh data dari rancangan dan alat ukur standar. Maka diperoleh hasil nilai akurasi dari alat ukur rancangan yang dibandingkan dengan alat ukur standar. Hasil dari masing-masing beban pada perangkat elektronik dapat dilihat pada Tabel 3. 
Jurnal ELECTRON, Vol. 2, No.2, November 2021, Hal. 69-78

e-ISSN 2622-6588 / p-ISSN 2830-523X

DOI: 10.33019\electron.v2i2.2

Tabel 3 Hasil Pengujian Nilai Akurasi Pada Faktor

\begin{tabular}{|c|c|c|c|c|}
\hline \multirow{2}{*}{ No } & \multirow{2}{*}{ Beban } & $\begin{array}{c}\text { Faktor Daya } \\
\text { rat rata- } \\
\text { rakur } \\
\text { ukuncangan }\end{array}$ & $\begin{array}{c}\text { Nilai rata- } \\
\text { rata alat } \\
\text { ukur } \\
\text { standar }\end{array}$ & $\begin{array}{c}\text { Akurasi } \\
\mathbf{( \% )}\end{array}$ \\
\hline 1 & $\begin{array}{c}\text { Lampu } \\
\text { Led 12W }\end{array}$ & 0.637 & 0.630 & 98.89 \\
\hline 2 & $\begin{array}{c}\text { Kipas } \\
\text { Angin } \\
35 \mathrm{~W}\end{array}$ & 0.532 & 0.533 & 99.81 \\
\hline 3 & $\begin{array}{c}\text { Televisi } \\
55 \mathrm{~W}\end{array}$ & 0.647 & 0.637 & 98.43 \\
\hline 4 & $\begin{array}{c}\text { Ricecooker } \\
350 \mathrm{~W}\end{array}$ & 0.990 & 0.987 & 99.7 \\
\hline 5 & $\begin{array}{c}\text { Charger } \\
\text { Laptop } \\
45 \mathrm{~W}\end{array}$ & 0.542 & 0.518 & 95.37 \\
\hline \multicolumn{4}{|c|}{ Akurasi Rata-rata } \\
\hline
\end{tabular}

Daya

Berdasarkan Tabel 3 dapat dilihat bahwa pengujian menggunakan alat ukur rancangan dengan menggunakan beberapa beban, yang dibandingkan dengan alat ukur standar. dapat dilihat nilai faktor daya rata-rata dari masing-masing beban yang terukur pada alat ukur rancangan dan juga alat ukur standar. Untuk menghitung persentase nilai akurasi didapatkan sebagai berikut.

$$
\begin{aligned}
\% \text { akurasi rata-rata } & =\frac{\sum \% \text { akuras: }}{5 \text { akurasi rata-rata }}=\frac{492.2^{\mathrm{n}}}{5} \\
\% \text { akurasi rata-rata } & =98.44 \%
\end{aligned}
$$

Sebagai contoh perhitungan menggunakan beban Lampu led. Persentase akurasi arus sebesar 98.89\%. persentase nilai kesalahan yang diakibatkan kesalahan pembacaan dari alat ukur rancangan terhadap alat ukur standar. Dan dapat juga disebabkan karena nilai arus pada beban yang sangat kecil, pada saat pengukuran faktor daya sehingga terdapat selisih pengukuran yang masih dalam tahap yang wajar. Persentase nilai akurasi rata-rata dalam pengukuran alat ukur rancangan terhadap alat ukur standar sebesar $98.44 \%$. Persentase kesalahan dalam pengujian pengukuran pembacaan arus yang terbaca pada alat ukur adalah sebesar $1.56 \%$. Dan berdasarkan referensi yang bersumber dari buku sudjana safiie[5] nilai kesalahan tersebut masih dalam batas yang wajar karena kurang dari 5\%.

3. Hasil pengujian nilai akurasi konsumsi energi

Setelah dilakukan pengambilan data dari masingmasing beban yang berbeda dengan menggunakan alat ukur rancangan dan alat ukur standar, data yang telah diperoleh menghasilkan persentase nilai akurasi. Pengukuran persentase nilai akurasi dilakukan dengan waktu 60 menit. Hasil yang telah diperoleh dapat dilihat pada Tabel 4.

\begin{tabular}{|c|c|c|}
\hline \multirow{2}{*}{ Beban } & $\begin{array}{c}\text { Alat ukur } \\
\text { rancangan (kWh) }\end{array}$ & $\begin{array}{c}\text { Alat ukur } \\
\text { standar (kWh) }\end{array}$ \\
\cline { 2 - 3 } & $\begin{array}{c}\text { Pengukuran 60 } \\
\text { menit }\end{array}$ & $\begin{array}{c}\text { Pengukuran 60 } \\
\text { menit }\end{array}$ \\
\hline Lampu Led 12W & 0.010 & 0.010 \\
\hline Kipas Angin 35W & 0.034 & 0.032 \\
\hline Televisi 55W & 0.038 & 0.038 \\
\hline Ricecooker 350W & 0.134 & 0.132 \\
\hline $\begin{array}{c}\text { Charger Laptop } \\
\text { 45W }\end{array}$ & 0.026 & 0.025 \\
\hline Total Energi & 0.242 & 0.237 \\
\hline
\end{tabular}

Tabel 4 Hasil Pengujian Nilai Akurasi Pada Konsumsi Energi

Pada Tabel 4 di atas, merupakan pengujian konsumsi energi listrik dari masing-masing beban yang berbeda dengan menggunakan alat ukur rancangan dengan alat ukur standar. Pengujian tersebut dilakukan dalam waktu 60 menit. Untuk menghitung nilai akurasi dapat dilihat menggunakan persamaan Persentase akurasi energi.

Akurasi $=100 \%$-galat

$\%$ kesalahan $=\left|\frac{\text { Total UR } \mathrm{XWh}_{\mathrm{XWh}}-\text { TotalUS }_{\mathrm{WWh}}}{\text { Total US }_{\mathrm{KWWh}}}\right| \times 100 \%$

$\%$ kesalahan $=\left|\frac{0.242-0.237}{0.237}\right| \times 100 \%$

$\%$ kesalahan $=2.11 \%$

Akurasi energi $=100 \%-2.11 \%$

Akurasi energi $=97.89 \%$

Dari hasil perhitungan di atas, didapatkan hasil persentase nilai akurasi pada masing-masing beban yang berbeda dengan konsumsi energi dalam waktu 60 
menit. Hasil dari nilai simpangan energi total dalam waktu 60 menit sebesar $97.89 \%$.

Prototipe sistem monitoring energi listrik ini mampu menghitung nilai konsumsi energi pada setiap bebannya. Tujuan dari monitoring $\mathrm{kWh}$ ini agar para konsumen energi listrik dapat menentukan estimasi biaya dari pemakaian beban-beban yang terpasang pada sumber listrik PLN. Adapun nilai konsumsi energi pada beban-beban yang berbeda bisa dilihat pada Gambar 4.

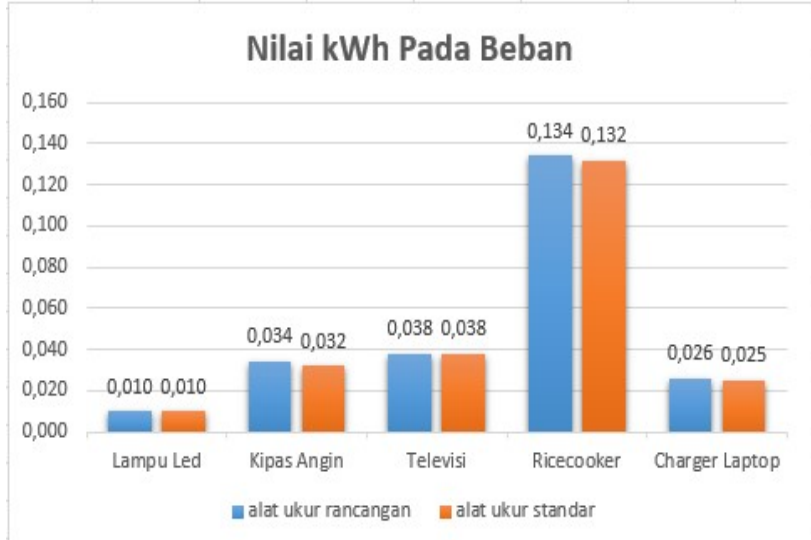

Gambar 4 Grafik Nilai Konsumsi Energi Pada Beban

\section{Hasil Pengujian Pada Ubidots}

Pengujian tampilan pada web Ubidots bertujuan untuk mengetahui data sensor dalam tampilan grafik serta mengetahui kerja infrastruktur pada Ubidots telah berfungsi baik atau tidak. Pengujian ini dilakukan dengan menampilkan hasil data pembacaan sensor yang diterima Ubidots. Pada Gambar 5 merupakan contoh tampilan dari grafik tegangan pada Ubidots yang mengukur beban dari ricecooker.

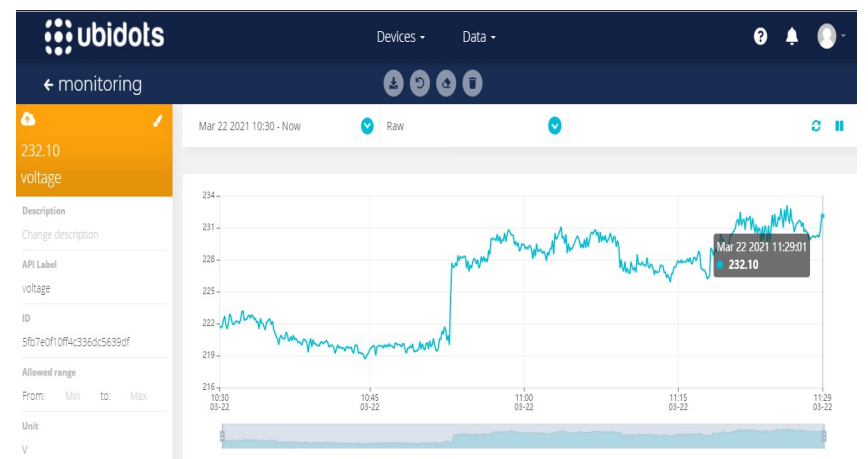

Gambar 5 Grafik Tegangan Pada Ubidots
Prototipe sistem monitoring energi listrik ini menampilkan biaya pemakaian dari beban-beban yang tehubung pada sumber listrik PLN. Perhitungan tarif biaya pemakaian listrik dilakukan

\begin{tabular}{|l|l|l|c|l|c|c|}
\hline NO & Beban & $\begin{array}{l}\text { Daya } \\
\text { (W) }\end{array}$ & $\begin{array}{l}\text { Durasi } \\
(\mathbf{J a m})\end{array}$ & $\begin{array}{l}\text { Total } \\
\mathbf{k W h} \\
\text { Sehari }\end{array}$ & $\begin{array}{c}\text { Total } \\
\mathbf{k W h} \\
\text { Sebula } \\
\mathbf{n}\end{array}$ & $\begin{array}{c}\text { Biaya } \\
\text { Pemakaia } \\
\mathbf{n}(\mathbf{R p})\end{array}$ \\
\hline 1 & $\begin{array}{l}\text { Lampu } \\
\text { Led }\end{array}$ & 12 & 6 & 0.06 & 1,8 & 2.438 .2 \\
\hline 2 & $\begin{array}{l}\text { Kipas } \\
\text { Angin }\end{array}$ & 35 & 6 & 0.204 & 6,12 & 8.274 .2 \\
\hline 3 & $\begin{array}{l}\text { Televis } \\
\text { i }\end{array}$ & 55 & 6 & 0.228 & 6,84 & 9.247 .7 \\
\hline 4 & $\begin{array}{l}\text { Riceco } \\
\text { oker }\end{array}$ & 350 & 6 & 0,084 & 24,12 & 32.610 .2 \\
\hline 5 & $\begin{array}{l}\text { Charge } \\
r\end{array}$ \\
$\begin{array}{l}\text { Laptop } \\
\text { Total Sebulan }\end{array}$ & 45 & 6 & 0.156 & 4,68 & 6.327 .4 \\
\hline \multicolumn{7}{|c|}{} \\
\hline
\end{tabular}

dengan cara nilai $\mathrm{kWh}$ pada beban dikalikan dengan tarif biaya konsumsi listrik yang telah ditetapkan pemerintah per-kWh nya. Adapun biaya pemakaian masing-masing beban dapat dilihat pada Tabel 5.

Tabel 5 Daftar Biaya Pemakaian Pada Beban

Pada Tabel 5 menunjukan bahwa biaya konsumsi energi listrik yang paling besar adalah ricecooker dan biaya terendah adalah lampu led. Pemakaian beban yang menyerap energi listrik paling besar akan menghasilkan nilai $\mathrm{kWh}$ yang besar juga, dan menyebabkan biaya konsumsi akan mengikuti besar dan kecilnya nilai $\mathrm{kWh}$. Oleh sebab itu, penghematan energi harus dilakukan dengan meminimalisir pemakaian energi listrik dengan cara menggunakan energi listrik seperlunya saja. Alat monitoring energi listrik ini mampu menampilkan dari pembacaan nilai tegangan dan arus. Nilai tegangan dan arus tersebut dikalkulasikan menjadi nilai $\mathrm{kWh}$ dan biaya konsumsi listrik dapat dilihat pada Gambar 6. 
Jurnal ELECTRON, Vol. 2, No.2, November 2021, Hal. 69-78

e-ISSN 2622-6588 / p-ISSN 2830-523X

DOI: $10.33019 \backslash$ electron.v2i2.2

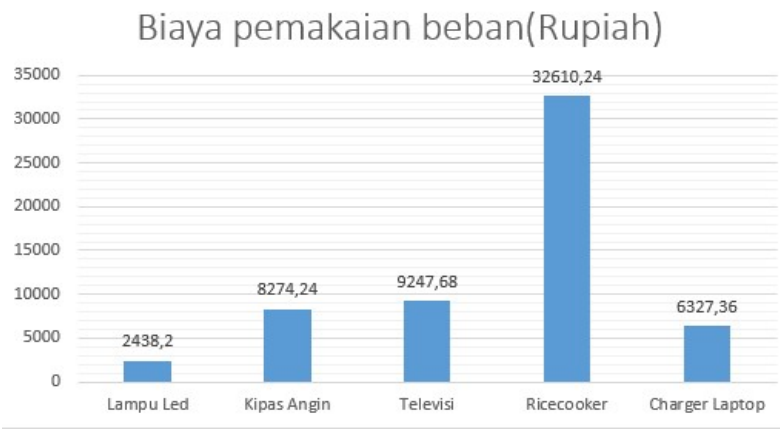

Gambar 6 Grafik Biaya Pemakaian Beban

Pengujian ini dilakukan pada rumah kontrakan dengan daya terpasang pada $\mathrm{kWh}$ meter $900 \mathrm{VA}$ sistem satu fasa yang termasuk dalam golongan R1M/TR (Rumah Tangga Mampu). Perhitungan penggunaan beban peralatan rumah tangga diantaranya: ricecooker, lampu led, kipas angin, televisi tabung, dan juga charger laptop. Pengujian yang dilakukan dari masing-masing beban digunakan untuk mengetahui nilai dari parameter listrik dan konsumsi energi. Pengujian alat ini tidak dilakukan dengan menggunakan rekening minimum. Rekening minum menggunakan persamaan Rekening Minimum: RM1 $=40$ jam nyala $\times$

daya tersambung $\times$ biaya pemakaian

RM1 $=40 \times 0.9 \times 1352$

RM1 $=\mathbf{R p} 48.672$ (empat puluh delapan ribu enam ratus tujuh puluh dua rupiah)

Jumlah biaya administrasi bank menentukan dimana konsumen membayar tagihan listrik. Besarnya antara Rp 2000 s/d Rp 3500. PJJ (Pajak Penerangan Jalan) ditentukan besarnya di dalam presentase misal $8 \%$ dari total $\mathrm{kWh}$ yang dibayar, dalam penelitian kali ini total $\mathrm{kWh}$ yang dibayar sebesar Rp 58.897.72. Besarnya PPJ (Pajak Penerangan Jalan) berbeda di tiap penjuru daerah, karena diberlakukan oleh pemerintah daerah melalui perda yang diciptakan. Komponen ini merujuk pada TDL (Tarif Dasar Listrik) atau TTL (Tarif Tenaga Listrik) yang ditetakan oleh pemerintah dan berlaku nasional. Biaya PJJ dapat dihitung dengan persamaan Biaya PPJ $8 \%=0.08 \times 58.897 .72$

Biaya PPJ $8 \%=$ Rp 4.711 .8 (Empat ribu tujuh ratus sebelas delapan rupiah)

Maka total estimasi biaya keseluruhan dari penggunaan beban peralalatan rumah tangga yang harus dibayarkan dalam waktu satu bulan adalah $\mathrm{Rp}$
114.781.52. Sedangkan jumlah tagihan sebenarnya yang ditagihkan oleh PLN sebesar Rp 113.567.7.

\section{KESIMPULAN}

Prototipe sistem monitoring energi sudah dapat dibuat dengan baik dan terbukti sistem dapat mengukur dan menampilkan hasil pengukuran nilai tegangan, arus, daya aktif, faktor daya, konsumsi energi listrik dan estimasi biaya yang harus dibayarkan. Besar persentase nilai akurasi dari sistem yang dirancang terhadap alat ukur standar meliputi: Tegangan sebesar $98.94 \%$, arus sebesar $99.18 \%$, daya aktif sebesar $98.87 \%$, faktor daya sebesar $98.44 \%$, dan perhitungan total konsumsi energi listrik sebesar 97.89\%. Dari hasil perhitungan selama 30 hari didapatkan jumlah konsumsi energi sebesar 43.56 $\mathrm{kWh}$ dengan nominal pembayaran atau estimasi biaya sebesar Rp 114.781.52 dengan jumlah tagihan sebenarnya yang ditagihkan oleh PLN sebesar 113.567.7.

\section{REFERENSI}

[1] F. N. Habibi, S. Setiawidayat and M. Mukhsim, "Alat Monitoring Pemakaian Energi Listrik Berbasis Android," Prosiding Seminar Nasional Teknologi Elektro Terapan, pp. 01(01), 157-162, 2017.

[2] A. V. Meier, ELECTRIC POWER SYSTEMS, New Jersey: EME Technologies, 2006.

[3] A. Shrivastava, "IoT and AI: Introduction to the Internet of Intelligent Things (IoIT)," 14 March 2019. [Online]. Available: https://dzone.com/articles/iot-amp-ai-theinternet-of-intelligent-things-ioit.

[4] H. Shull, "SISTEM PENGAMANAN PINTU RUMAH BERBASIS Internet Of Things (IoT) Dengan ESP8266," Science (80-. )., vol. 195, no. 4279, p. 639, 1977, [Online]. Available:

https://ojs.uniskabjm.ac.id/index.php/JIT/artic le/view/661.

[5] S. Sapiie and N. Osamu, Pengukuran dan alat Ukur Listrik, Jakarta: Pradya Paramita, 1994.

[6] Hidayat, A. D., Sudibya, B., \& Waluyo, C. B. (2019). Pendeteksi tingkat kebisingan berbasis internet of things sebagai media kontrol kenyamanan ruangan perpustakaan. Avation 
Jurnal ELECTRON, Vol. 2, No.2, November 2021, Hal. 69-78

e-ISSN 2622-6588 / p-ISSN 2830-523X

DOI: $10.33019 \backslash$ electron.v2i2.2

Electronics, Information Technology, Telecommunications, Electricals, and Controls, 1(1), 99-108.

[7] Waluyo, C. B. (2018). Design and Development of $72.83 \mathrm{MHz}$ Signal Booster Transmitter to increase the remote control coverage. Angkasa: Jurnal Ilmiah Bidang Teknologi, 10(2), 122-129.

[8] T. Nusa, "Sistem Monitoring Konsumsi Energi Listrik Secara Real Time Berbasis Mikrokontroler," E-journal Teknik Elektro dan Komputer, pp. 4(5), 19-26, 2015.

[9] D. Handarly, "Sistem Monitoring Konsumsi Daya Listrik Jarak Jauh Berbasis Internet of Things," Journal of Electrical Electronic Control and Automotive Engineering (JEECAE), pp. 3(2), 205-208, 2018.

[10] Alipudin, A. M, "Rancang bangun alat monitoring biaya listrik terpakai berbasis internet of things (iot)," Jurnal Online Mahasiswa (JOM) Bidang Teknik Elektro, 1(1). 